\title{
RECONSTRUCCIÓN DE LABIO INFERIOR CON TÉCNICA DE KARAPANDZIC
}

\section{LIP LOWERRECONSTRUCTION WITH KARAPANDZIC'S TECHNIQUE}

\author{
Celso Aldana ${ }^{1}$, María Elsa Meza ${ }^{2}$, Elvio Méndez $z^{3}$ José Sandoval ${ }^{4}$
}

\section{RESUMEN}

La región de los labios representa una zona anatómica de interés debido a que tiene una frecuencia importante de patología tumoral. Su reconstrucción es un desafío ya que se debe lograr un buen resultado tanto funcional como estético.Debido a esto, se han descrito numerosas técnicas para la reconstrucción de esta zona. Nosotros seguimos una técnica basada en la preservación anatómica de los pedículos faciales que mantiene la irrigación y la funcionalidad futura del labio.

Palabras clave: Carcinoma epidermoide, colgajo de karapanzic.

\section{ABSTRACT}

The region of the lips represents an anatomical area of interest because it has an important frequency of tumoral pathology. Its reconstruction is a challenge since it must achieve a good result both functional and aesthetic. Because of this, numerous techniques have been described for the reconstruction of this area. We follow a technique based on the anatomical preservation of the facial pedicles that maintains the irrigation and the future functionality of the lip.

Key words: squamous cell carcinoma, karapanzic flap.

\section{INTRODUCCIÓN}

La patología tumoral es frecuente a nivel de los labios. La reconstrucción de esta región anatómica requiere la utilización de técnicas quirúrgicas estratégicamente diseñadas, aplicadas por un especialista competente, que permitan la obtención de un resultado estético y funcional favorable. Entre tantas opciones terapéuticas, la calidad de vida de un paciente puede depender de una criteriosa elección por parte del cirujano plástico, en cuanto a técnica reparadora se refiere. Por lo tanto es interesanteconsiderar aquella que pueda adaptarse de la mejor manera posible a esta zona tan especial de la anatomía facial.

El presente trabajo tiene como objetivo reportar un caso clínico de reconstrucción de labio inferior, en donde se utilizó como opción terapéutica el método de Karapandzic.

\section{REPORTE DE CASO}

Paciente masculino de 79 años que consulta por lesión vegetante de labio inferior de 4 años de evolución. La lesión fue creciendo lentamente hasta llegar a ocupar el 65\% del labio inferior, con medidas de $7 \times 5 \mathrm{~cm}$. de diámetro. No se palpaban adenopatías regionales (Fig. 1 al 3).Se realizó una biopsia incisional cuyo informe anatomopatológico reportó un carcinoma epidermoide infiltrante bien diferenciado (grado 1) queratinizante, ulcerado. Se decidió realizar la extirpación de la lesión, bajo anestesia general, y reconstrucción con técnica de Karapandzic.

\section{TÉCNICA QUIRÚRGICA}

Basándonos en la descripción de Miodrag Karapandzic ${ }^{(1)}$, se realiza la marcación del área a extirpar con los respectivos colgajos a utilizar (Fig. 4).

Se extirpa la lesión tumoral con un margen de seguridad de $1 \mathrm{~cm}$. (Fig. 5 y 6).Se diseca cuidadosamente los colgajos miocutáneos, identificando y respetando tanto los elementos vasculares como nerviosos. Este método permite el avance cutaneo-muscular dejando intacta la mucosa subyacente, constituyendo colgajos remarcadamente móviles que pueden alcanzar con fiabilidad la zona a reconstruir. Se realiza una hemostasia cuidadosa y se procede a realizar la sutura por planos de los colgajos rotados. No dejamos drenajes. El periodo postoperatorio aconteció sin ningún tipo de inconveniente, con preservación de la sensibilidad de la zona operatoria. Se obtuvo un resultado satisfactorio tanto desde el punto de vista funcional como estético (Fig 7 y 8).

\section{DISCUSIÓN}

Como describen diferentes autores ${ }^{(2)}$, no existe un método ideal para la reconstrucción de los labios. Si la lesión ocupa hasta $1 / 3$ del borde del labio, el cierre puede ser realizado en forma direc-

Universidad Nacional de Asunción, Facultad de Ciencias Médicas, Hospital de Clínicas, Unidad de Cirugía Plástica.(FCM-UNA), Paraguay

1. Prof. Dr., Jefe de Servicio, cirujano plástico y coordinador del postgrado de cirugía plástica;

2. Dra., cirujana plástica y docente;

3. Dr., residente de cirugía plástica;

4. Dr., residente de cirugía plástica.

Autor correspondiente: Dr. José Sandoval-Unidad de Cirugía Plástica, FCM-UNA. Email: sandovalperez@hotmail.com.

Artículo recibido: 11.07 .18 - Artículo aceptado: 23.08 .18 

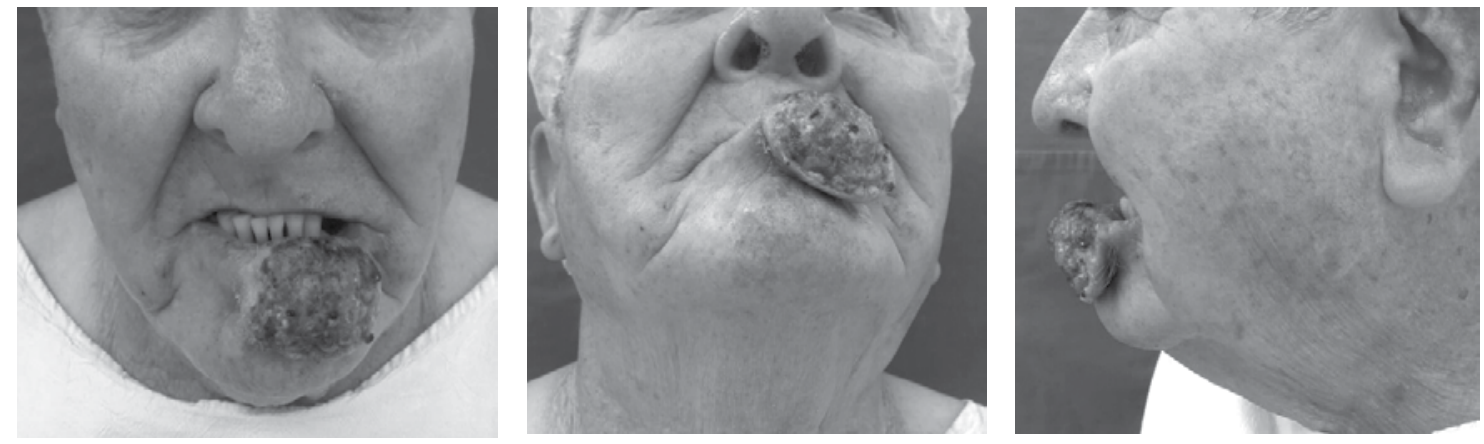

Figuras 1 al 3. Lesión vegetante en labio inferior.

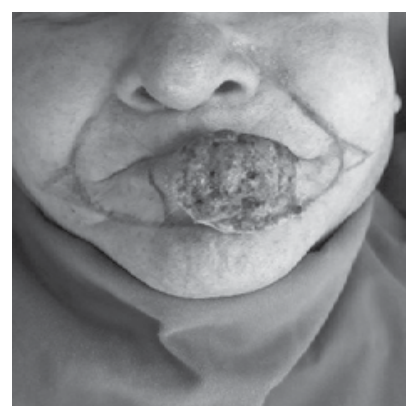

Figura 4. Marcación pre-operatoria.
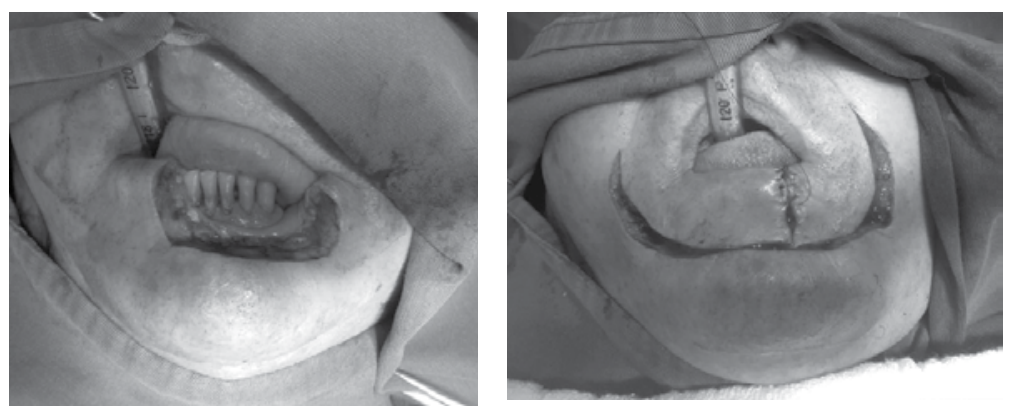

Figura 5 y 6. Excéresis tumoral con margen de seguridad.
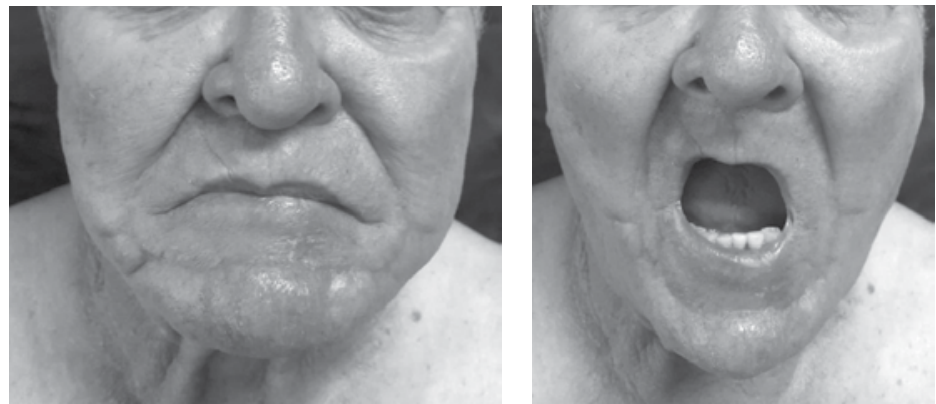

Figura 7 y 8 . Post-operatorio.

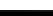


ta, o se puede recurrir a plastía en W. Cuando la lesión ocupa más del 35\% del labio, se precisa para el cierre reconstrucción con colgajos ${ }^{(3,4)}$. La mayoría de ellos utilizan piel de las zonas próximas como son el labio no afectado tipo Abbe ${ }^{(5)}$, de la mejilla tipo Guillies o Estlander ${ }^{(4)}$, del mentón tipo Bernard, etc.

La técnica elegida por nosotros proporciona como ventajas, en lesiones de dimensiones considerables, la realización en un solo tiempo quirúrgico y la preservación de una importante red vasculonerviosa que permite una amplia seguridad tisular, con colgajos móviles y sensibles ${ }^{(6-8)}$.

Los mejores resultados con la técnica de Karapandzicse obtienen cuando la lesión se encuentra en el centro de los labios.
En efecto, si el defecto interesa la comisura bucal los resultados no son satisfactorios.

La microstomía postoperatoria constituye el principal inconveniente descrito para esta técnica ${ }^{(8)}$. $\mathrm{Al}$ respecto, aproximadamente entre el 12 al 15\% de los casos requieren una comisuroplastia ulterior correctiva.

En ese sentido, en el presente caso reportado no objetivamos inconveniente alguno, obteniendo más bien una apertura bucal correcta y satisfactoria.

En conclusión, el método de Karapandzic contribuyó a restituir en nuestro paciente la anatomía y fisiología que estaban comprometidas en el labio inferior.

\section{BIBLIOGRAFÍA}

1. Karapandzic M. "Reconstruction of lip defects by arterial flaps". Br J Plast Surg. 1974; 27(1):93.

2. Jabaley ME, Orcutt TW Clement RL. "Applications of the Karapandzic principle of lip reconstruction after excision of lip cancer". Am J Surg. 1976; 132(4):529.

3. Nzakamwita M, Linker M, Gitani J, Piert R. "Repair of tissue loss of the lips". Acta Stomatol Belg. 1995; 92(4): 159.

4. Abulafia AJ, Edilberto L, Fernanda V. "Reconstruction of the lower lip and chin with local flaps”. Plast Reconstr Surg. 1996; 97(4):847.
5. Calhoun KH. "Reconstruction of small- and medium- sized defects of the lower lip". Am J Otolaryngology. 1992; 13(1):16.

6 Kroll SS. "Staged sequential flap reconstruction for large lower lip defects”. Plast Reconstr Surg. 199; 88(4):620; discussion 626.

7. Jabaley ME, Clement RL, Orcutt TW. "Myocutaneus flaps in lip reconstruction. Applications of the Karapandzic principle”. Plast Reconstr Surg. 1977; 59(5):680.

8. Hills RJ. "Innervated musculocutaneous lip flap (Karapandzic technique)”. Australas J Dermatol. 1998; 39(3):190. 